\title{
Metabolic Syndrome: Consensus and Controversy: State of the Art
}

\author{
Hamilton dos Prazeres Tavares' ${ }^{1}$, Rafael Bottaro Gelaleti' ${ }^{1}$ Fernanda Picolo', \\ Suelma Beatriz Marques Prata Tavares ${ }^{2}$, Gabriela Marini ${ }^{3}$, Joelcio Francisco Abbade ${ }^{1}$, \\ Debora Cristina Damasceno Meirelles dos Santos ${ }^{1}$, Paulo Adão de Campos ${ }^{4}$, \\ Iracema de matos Paranhos Calderon', Marilza Vieira Cunha Rudge ${ }^{1}$ \\ ${ }^{1}$ Department of Gynecology and Obstetrics, Botucatu Medical School, UNESP-Universidade Estadual Paulista, \\ Botucatu, Brazil \\ ${ }^{2}$ Department of Gynecology and Obstetrics of the Municipal Hospital of Huambo, Huambo, Angola \\ ${ }^{3}$ University of Sacred Heart (USC), Bauru, Brazil \\ ${ }^{4}$ Departament of Gynecology and Obstetric in Medical School, Agostinho Neto University, Luanda, Angola \\ Email: hamitavares@hotmail.com
}

Received 21 July 2015; accepted 27 September 2015; published 30 September 2015

Copyright (C) 2015 by authors and Scientific Research Publishing Inc.

This work is licensed under the Creative Commons Attribution International License (CC BY).

http://creativecommons.org/licenses/by/4.0/

(c) (i) Open Access

\section{Abstract}

Metabolic syndrome is an epidemic that affects more and more people, increasing the probability of suffering metabolic and cardiovascular diseases in the short, medium or long term depending on the severity. The purpose of this article is to review the metabolic syndrome, assessing consensus, controversy and prevalence. The methodology was the preparation of a literature review on various health care databases, which were from 43 articles published from 2010 to 2015 , in the general population. SM rate ranges from $0 \%$ to $90 \%$ depending on genders, ages and regions. There is still lack of consensus on cutoffs of diagnostic criteria. Thus, it is concluded that the prevalence of metabolic syndrome is being increased, urging the need for early diagnosis and treatment to promote the health of the global population.

\section{Keywords}

Metabolic Syndrome X, Prevalence, Consensus

\section{Introduction}

As the profile of the population in the world is being changed and researchers are trying to understand the causes involved in Metabolic Syndrome, a lot of researches have been developed to understand the situation. In the 30 studies, they have been developed in an attempt to understand the sensitivity that some people (thin, fat and old) 
have used insulin [1].

The metabolic syndrome (MetS) is a set of metabolic abnormalities that give the individual a number of risks for metabolic and cardiovascular diseases [2].

This study is to demonstrate the very latest on conduct in metabolic syndrome and respectively their disputes.

\section{Metabolic Syndrome}

Metabolic syndrome is considered as the new epidemic of the twenty-first century. Its appearance depends on several factors that are being studied and gathered on clinical criteria for investigation.

This has been addressed in several studies, since the biophysical profile of the population has being changed and influenced by lifestyles, market demands, industrialization, etc. Researchers are still trying to understand the situations about the metabolic syndrome, receiving assignments according to the findings, reasons why their names have been changed over the years, even when having a confluence point.

The association among high blood pressure, hyperglycemia and gout was described by Kylim in 1923 [1]. Following these surveys, it was conventional to get specific treatment for diabetes, since they knew about the insulin resistance and continued studies [3].

In 1966, Welborn and Modan studied and realized that the population concerned (fat/thin/diabetic/resistant/ insulin), besides these elements were hypertensive and had impaired glucose tolerance, describing association between hypertension and glucose intolerance [1] [4].

In addition to the signs and symptoms previously reported, hyperinsulinemia and dyslipidemia have been described as X syndrome, characterized by insulin resistance, glucose intolerance, hyperinsulinemia, blood hypertension and dyslipidemia. These problems appear frequently in one person. This situation makes greater risk of cardiovascular events, and this phenomenon is called syndrome $\mathrm{X}$ [5].

Those people with this clinical picture had high mortality rates, especially sudden conditions, therefore, they were subjected to autopsy to try to understand what was happening and was described as deadly quartet. During the examination of the corpses, atheromatous plaques were found in coronary arteries, the deadly quartet characterized by central obesity, glucose intolerance, hypertriglyceridemia and arterial blood-pressure disease coronariana [6].

This population has metabolic complications, in presenting cardiovascular clinical conditions in three to four times or more on all the perimenopause period, hence the design of cardiovascular metabolic syndrome [7] [8].

In describing the SM and making the clinical diagnosis of the population, it was noticed that the metabolic change was registered in the human body as a whole and not in a specific place, designed as Pluiri Metabolic syndrome, characterized by: centripetal obesity, glucose intolerance, hypertension characterized with compromised coronary arteries and hypertriglyceridemia [9].

In 1998, the first official definition and a list of criteria for the diagnosis of MetS were published with the cutoff assessment of insulin resistance or disorders in glucose metabolism. The criteria that caused the diagnosis of the syndrome were: hyperglycemia and/or insulin resistance with two or more of the following criteria: abdominal obesity, dyslipidemia, hypertension and microalbunuria [10].

MetS increases the risk of suffering cardiovascular disease (atherosclerosis and its complications) and metabolic secondarily morbidity and mortality by them.

For the people with diabetes mellitus, cardiovascular disease is a key element in your prognosis [11].

\section{Settings}

The literature has been changing the concept and what it encompasses to make diagnoses. Metabolic syndrome is characterized by the presence of hyperinsulinemia, insulin resistance, obesity, dyslipidemia, hypertension, type 2 diabetes mellitus and/or glucose decreased tolerance [12]-[15].

Metabolic syndrome is defined by a set of interconnected factors that directly increase the risk of coronary heart disease (CHD), other forms of Atherosclerosis Cardiovascular Diseases (CVD) and diabetes mellitus type $2[16]$.

\section{Diagnosis}

The consensus is that the diagnosis of metabolic syndrome needs to change at least 3 variables. The glucose intolerance and insulin resistance are key components in WHO [10], settings and EGIR [17]. Insulin resistance or 
fasting hyperinsulinemia plus two of the following-Hyperglycemia $>110 \mathrm{mg} / \mathrm{dl}$ but $<126 \mathrm{mg} / \mathrm{dl}$, blood pressure $\geq$ $140 / 90 \mathrm{~mm} / \mathrm{Hg}$, Dyslipidemia $>$ TG $180 \mathrm{mg} / \mathrm{dl}$ or C-HDL $<40 \mathrm{mg} / \mathrm{dl}$, Central obesity (waist $\geq 94 \mathrm{~cm}$ with the men and $\geq 80 \mathrm{~cm}$ in women [10] [17].

For Joint Interim Statement (JIS) it takes the presence of three or more of the following components: WC $\geq$ $94 \mathrm{~cm}$ (men), $80 \mathrm{~cm}$ (women); SBP $\geq 130 \mathrm{mmHg}$ and/or DBP $\geq 85 \mathrm{mmHg}$ and/or treatment of reducing blood pressure; triglyceride fasting levels $\geq 150 \mathrm{mg} / \mathrm{dl}(1.70 \mathrm{mmol} / \mathrm{L})$ or treatment for hypertriglyceridemia; HDL-C < $40 \mathrm{mg} / \mathrm{dl}(1.04 \mathrm{mmol} / \mathrm{L})(\mathrm{men}), 50 \mathrm{mg} / \mathrm{dl}(1.30 \mathrm{mmol} / \mathrm{l})$ (women) or treatment for dyslipidemia; Fasting blood glucose levels $\geq 100 \mathrm{mg} / \mathrm{dl}(5.55 \mathrm{mmol} / \mathrm{L})$ or anti diabetic drug [18].

Some experts defined as SM-bearing individuals with three of the followings: arterial hypertension, dyslipidemia, obesity, glucose intolerance (DM2) or impaired glucose tolerance, or insulin resistance plus two changes [19].

Or as any individual with: Central Obesity (waist $\geq 90 \mathrm{~cm}$ with the men and $\geq 80 \mathrm{~cm}$ in European women, with values for the various ethnic groups plus two of the following criteria: TG $>150 \mathrm{mg} / \mathrm{dl}$ or therapy for Hipertriglieridémia, $\mathrm{C}<$ of HDL $40 \mathrm{mg} / \mathrm{dL}$ in humans and $<50 \mathrm{mg} / \mathrm{dl}$ in women, or treatment for this anomaly, systolic BP $\geq 130 \mathrm{~mm} / \mathrm{Hg}$ or diastolic $\geq 85 \mathrm{~mm} / \mathrm{Hg}$, fasting blood glucose $>100 \mathrm{mg} / \mathrm{dL}$ or previously diagnosed $\mathrm{DM}$, dyslipidemia TG $>80 \mathrm{mg} / \mathrm{dl}$ or C-HDL $<40 \mathrm{mg} / \mathrm{dl}$ [8].

The frequently used definitions in clinical practice are proposed by the NCEP ATP III (IDF) and American Heart Association/National Heart, Lung and Blood Institute (AHA/NHLBI) [12].

While the Latin American consensus Diabetes defined as criteria for diagnosis: Obesity Central Perimeter waist men $\geq 94 \mathrm{~cm}$, women $\geq 88 \mathrm{~cm}$, plus the following four factors: Triglycerides $>150 \mathrm{mg} / \mathrm{dl}$, HDL c $=$ Men $<$ $40 \mathrm{mg} / \mathrm{dl}$, Women $<50 \mathrm{mg} / \mathrm{dl}$, blood pressure: Men > 130/85 mm Hg, specific treatment for certain disorders, abnormal blood glucose, oral tolerance test changed or Diabetes glucose [20].

The International Diabetes Federation (IDF) recently recommended settings for metabolic syndrome in children and adolescents, which is to have abdominal obesity and at least two of the other four components: hypertriglyceridemia, low HDL cholesterol, hyperglycemia and hipertensão [8].

\section{Consensus and Controversies}

Just to WHO and to the IDF, impaired glucose tolerance or insulin resistance are key components in the settings, whereas for other classifications no components considered fundamental, just have three elements changed.

A variety of classifications and cutoff points for the diagnosis of metabolic syndrome is an obstacle to propodêutica. The consensus in the use of criteria for the diagnosis of metabolic syndrome is: changes in lipid profile, blood pressure, fasting hyperglycemia, obesity [21].

However, the criteria is set for different populations of the same world, means that there is difference in prevalence rates, however waist circumference (WC) was recommended as a simple screening tool to measure abdominal obesity, in contrast to body mass index or other anthropometric measures. The cutoff point proposed by the ATP III was the subject of debate. This mainly depends on the ethnicity and gender. Several studies in Asian population particularly in China, Turkey and Iran show that the regional cutoff for proposed CC could have been more appropriate. The Iranian National Committee of Obesity (INCO) also proposed revised criteria ATP III regional value DC cut $>95 \mathrm{~cm}$ for men and women, these differences cutoffs cause even if there is consensus on the variables, there will still be the cutoff points. Also, there is a difference in blood glucose cut off NCEP ATP III (Glucose $\geq 110 \mathrm{mg} / \mathrm{dl}$ ) for JIS (Glucose $100 \mathrm{mg} / \mathrm{dl}$ ) [22].

These days, it is recommended the use of harmonized criteria (2009) for the diagnosis of metabolic syndrome, Joint Interim Statement (JIS) [22].

\section{Risk Factors}

More and more people in the world suffer obesity disease, and especially about $60 \%$ population in the North American. This growth also relates to higher incidence of Type 2 diabetes mellitus (MD2) in mundo [23].

Thus, the rate of cardiovascular disease and mortality increase dramatically. Changing lifestyles toward modernization and urbanization is directly proportional to the growing body rate of obesity and abdominal obesity. These factors are the main contributors to metabolic syndrome in adults and adolescentes [24].

A similar situation is observed in Africa, where most countries are under development, as the prevalence of MS is higher in first world countries and industrialized. In Africa, obesity, diabetes type 2 (T2MD) and atherosclerotic cardiovascular disease (CVD) are chronic diseases that affect the health system. In 2006, it was esti- 
mated that 10.8 million Africans suffered MD, and in 2025, it would be 18.7 million [25].

Yet with respect to the risks, relative aspects such as lifestyles and food [26]. The MS is usually associated with cardiovascular and metabolic diseases, and is the direct cause of morbidity and mortality in the United States and Brasil [27]. The prevalence of MS has been globally increased. It is estimated that $20 \%-25 \%$ of the world population is carrier of this syndrome [8].

In short the risk factors for metabolic syndrome are: less physical exercise; Poor diet; Abdominal obesity; dyslipidemia; Dysglycemia and Tabagismo [28].

\section{Epidemiology}

The prevalence of MS in adults in the United States, according to the diagnostic criteria of NCEP, was $6.7 \%$ in the age group 20 - 29 years $43.5 \% 60$ - 69 years and $42 \%$ largest among 70 years [29]. Independent of criteria for assessing the SM, it is estimated that nowadays about 100 million people on the planet suffer SM metabolic [7].

The MS prevalence ranges from $20 \%$ - 25\% among individuals with adequate weight for height, $50 \%$ in patients with dysglycemia $80 \%$ in patients with diabetes type $2 ; 12.4 \%$ to $28.5 \%$ in men and from $10.7 \%$ to $40.5 \%$ in women, the syndrome is more prevalent in women than men [11].

The prevalence of metabolic syndrome (MS) in childhood and adolescence this estimated at more and 3.3\% in the world [30].

The prevalence of MS is still unknown in Brazilian samples. Research conducted in adults in the cities of Vitória-ES and Virgin of Grace-MG, showed prevalence of MS of 29.8\% (men: 29.3\%; women: 30.1\%) and 21.6\% (men: 7.7\%; women: 33.6\%), respectively, and 28\% Brasilia [23].

In 2010, the prevalence of the syndrome in the clinic in the state of Rio de Janeiro by the IDF criteria was slightly higher than the NCEP (61.1\% vs $55.6 \%) 30$. They found frequency of metabolic syndrome in women $89.66 \%$ and $42.86 \%$ of men [31].

In 2011, it became public that about $8.9 \%$ of the adult men were already obese against $13.1 \%$ of women [32].

In 2013, while studying the number of components of the metabolic syndrome in a Brazilian adult population in a rural area it was more frequent among women (23.3\%) than among men (6.5\%) [33]. The prevalence of metabolic syndrome in Africa varies $0 \%-50 \%$ of the population in general [34].

Having been found in Angola crude prevalence of metabolic syndrome in two criteria: JIS (27.8\% adjusted for age $14.1 \%$ ) than with the definition of the ATP III (17.6\% adjusted for age 8.7\%) [35].

\section{Conduct}

Given the situation we need to take necessary actions, especially in relation to public health, it is the responsibility of the public. It is noticed that the developed countries and non-governmental organizations have helped systematically those who in need.

Today, it needs more investment in research, health promotion and disease prevention. The population or individual with metabolic syndrome should be evaluated and oriented mainly on issues relating to the change of lifestyle and medication.

Regarding the lifestyle changes, regular physical activity is a change in lifestyle that may influence favorably the results of cardiovascular health, including cardiovascular disease, stroke by stroke, hypertension, diabetes mellitus type 2, obesity and improvement in the lipid profile. However, if you want to promote and maintain health, 30 minutes of daily physical exercise, 5 days per week for adults 18 - 65 years of age, children and adolescent of 5 - 17 years of age, should do exercise at moderate intensity, for 60 minutes accumulated days [36].

Although there is no consensus on the most appropriate nutritional strategy to cure metabolic syndrome [30], good nutrition education, sometimes accompanied by nutritionists, especially when you are overweight, a balanced and controlled diet alternating with vegetables intake of leafy greens, fruits, vegetables, milk, and exercise, this behavior would improve MS way, so that even if the ideal weight for height, thus reducing the abdominal girth, blood pressure better, controlling blood glucose, improving LDL and LDH [37].

Individuals at any age presenting changes in lipid profile, metabolic disease (DM2), SM, admitted to outpatient State health services and/or private offices nutrition, medicine, pediatrics, endocrinology and others, should be targeted and/or followed according to actual conditions regarding preventive measures and treatment of diseases, rehabilitation of sequela, health promotion, as these may increase the longevity, interfering directly in the quality of life. Therapies of modifying the additional lipids such as fibrates, omega-3, polyunsaturated fatty acids, are capable of improving the lipid profile and further reducing the risk of CVD in those patients [23]. 


\section{Methodology}

We reviewed the situation of metabolic syndrome MetS, prevalence, risk factors, consensus, controversies in the literature in the general population. To support this review, surveys were conducted in 43 articles and in two books of obstetric publications from 2010 to 2015. PubMed, Lilacs, Medline, Embase, Scopus, CINAH and Science database were used to search for articles published on metabolic syndrome in general, consensus and controversy. We searched all those databases using the key words: metabolic syndrome, prevalence, 113 articles published in English and Portuguese.

All the identified articles were reviewed to find and avoid possible duplication and then arranged for further survey. By analyzing the titles of the articles, the ones whose design differed from inclusion criteria (metabolic syndrome, syndrome X, Prevalence, Consensus) were identified. Summaries of the articles were read and selected and we excluded those which did not mention the features of metabolic syndrome, prevalence, consensus. The complete text of selected articles were retrieved and reviewed independently. After data extraction, a new review of articles was made as a means to ensure that the data of the selected articles were included only once in the analysis, which resulted in only 43 remaining articles taking part with this review. The results are summarized according to sample size, type of study, the definition used for metabolic syndrome, Prevalence, consensus and controversy.

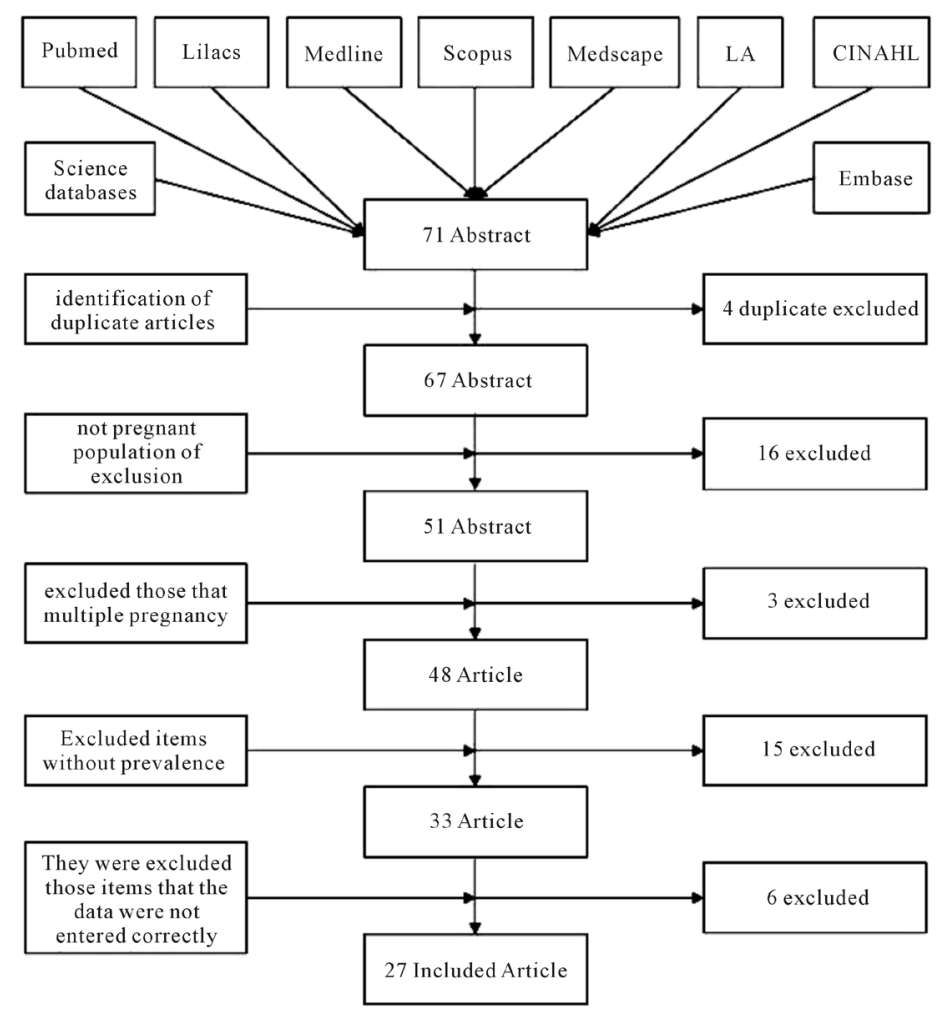

\section{Results}

Metabolic syndrome continues to rise on the planet, even though it is a global concern and considered epidemic of the XXI century where almost all countries regard it as a public health problem. It is more prevalent in adults and females.

While there are several criteria and diagnostics for metabolic syndrome, it is agreed that for such an individual it has to have at least three elements of the change in the criteria used. There is no consensus on cutoffs.

The investigation of the presence of risk factors for the syndrome is an opportunity to prevent disasters on public health.

Despite the power of intervention of discord on the benefits of certain foods for the prevention of cardiovascular events in people with the installed phenomenon, it is still recommended by most authors. 
The consensus is the practice of physical activity for glycemic control, lipid profile and body mass index.

Although there exist many criteria and cutoff points for the diagnosis of metabolic syndrome, a lot of researchers try to cross several criteria, and conclude and harmonize the various definitions and conclude that the most appropriate criteria for themetabolic syndrome diagnosis are the JIS (2009).

\section{References}

[1] Negrato, C.A., Javanovic, L., Tambascia, M.A., Calderon, I.M.P., Geloneze, B., Dias, A., et al. (2008) Mild Gestacional Hyperglycemia as a Risk Factor for Metabolic Syndrome in Pregnancy and Adverse Perinatal Outcomes. Diabetes/Metabolism Research and Reviews, 24, 324-330. http://dx.doi.org/10.1002/dmrr.815

[2] Grundy, S.M., Brewer Jr., H.B., Cleeman, J.I., Smith Jr., S.C., Lenfant, C., et al. and American Heart Association (2004) Definition of Metabolic Syndrome: Report of the National Heart, Lung, and Blood Institute/American Heart Association Conference on Scientific Issues Related to Definition. Circulation, 109, 433-438. http://dx.doi.org/10.1161/01.CIR.0000111245.75752.C6

[3] Isomaa, B., Almgren, P., Tuomi, T., Forsén, B., Lahti, K., Nissén, M., et al. (2001) Cardiovascular Morbidity and Mortality Associated with the Metabolic Syndrome. Diabetes Care, 24, 683-689. http://dx.doi.org/10.2337/diacare.24.4.683

[4] Negrato, C.A., Tambascia, M., Calderon, I.M.P., Pauletti, T.A.L. and Rudge, M.V.C. (2007) Current Diagnostic Criteria of the Metabolic Syndrome. Femina, 35, 623-629.

[5] Reaven, G.M. (1988) Role of Insulin Resistance in Human Disease. Diabetes, 37, 1595-1607. http://dx.doi.org/10.2337/diab.37.12.1595

[6] Kaplan, N.M. (1989) The Deadly Quartet. Upper-Body Obesity, Glucose Intolerance, Hypertriglyceridemia, and Hypertension. Archives of Internal Medicine, 149, 1514-1520. http://dx.doi.org/10.1001/archinte.1989.00390070054005

[7] Drebes, C., Hentschke, M., Cioffi, L., Furlanetti, T., Costa, B.E.P., Figueiredo, C.E.P., et al. (2009) Gestational Hypertension Disease and Metabolic Syndrome [Internet]. X Hall Scientific Initiation PUCRS. http://www.pucrs.br/edipucrs/XSalaoIC/Ciencias_da_Saude/Medicina/70586-CHRISTIANVALMORENGSTERDRE BES.pdf

[8] International Diabetes Federation (2015) The IDF Consensus Worldwide Definition of the Metabolic Syndrome [Internet]. https://www.idf.org/webdata/.../IDF_Meta_def_final

[9] Bouchard, C. and Perusse, L. (1993) Genetics of Causes and Manifestations of the Metabolic Syndrome. In: Crepaldi, G., Tiengo, A. and Manzato, E., Eds., Diabetes, Obesity and Hyperlipidemia: The Plurimetabolic Syndrome, Elsevier Science, Amsterdam, 67-74.

[10] World Health Organization (1999) [Internet]. Definition, Diagnosis and Classification of Diabetes Mellitus and Its Complications: Report of a WHO Consultation. Part 1: Diagnosis and Classification of Diabetes Mellitus. World Health Organization. Geneva. www.who.int/diabetes/publications/Definition\%20an

[11] Araújo, J.R., Martel, F. and Keating, E. (2014) Exposure to Non-Nutritive Sweeteners during Pregnancy and Lactation: Impact in Programming of Metabolic Diseases in the Progeny Later in Life. Reproductive Toxicology, 49, $196-201$. http://dx.doi.org/10.1016/j.reprotox.2014.09.007

[12] Teixeira, C.S.M. (2009) Metabolic Syndrome in Pregnancy as Predictor of Adverse Obstetric and Neonatal Outcomes. Master's Dissertation, Institute of Biomedical Sciences Abel Salazar, University of Porto, Porto. www.icbas.up.pt/biblioteca/images/.../boletim\%20bibliogrfico03.pdf

[13] Ceballos, L.T. (2007) Metabolic Syndrome en la Childhood. Anales de pediatría, 66, 159-166.

[14] Vishram, J.K., Borglykke, A., Andreasen, A.H., Jeppesen, J., Ibsen, H., Jørgensen, T., et al. (2014) Impact of Age and Gender on the Prevalence and Prognostic Importance of the Metabolic Syndrome and Its Components in Europeans. The MORGAM Prospective Cohort Project. PLoS ONE, 9, e107294. http://dx.doi.org/10.1371/journal.pone.0107294

[15] Al-Nasiry, S., Ghossein-Doha, C., Polman, S.E.J., Lemmens, S., Scholten, R.R., Heidema, W.M., et al. (2014) Metabolic Syndrome after Pregnancies Complicated by Pre-Eclampsia or Small for Gestational Age: A Retrospective Cohort. BJOG, Epub Ahead of Print. http://dx.doi.org/10.1111/1471-0528.13117

[16] Kassi, E., Pervanidou, P., Kaltsas, G. and Chrousos, G. (2011) Metabolic Syndrome: Definitions and Controversies. BMC Medicine, 9, 48. http://dx.doi.org/10.1186/1741-7015-9-48

[17] Balkau, B. and Charles, M.A. (1999) Comments on the Provisional Report from the WHO Consultation: European Group for the Study of Insulin Resistance (EGIR). Diabetic Medicine, 16, 442-443. http://dx.doi.org/10.1046/j.1464-5491.1999.00059.x

[18] Alberti, K.G.M.M., Eckel, R.H., Grundy, S.M., Zimmet, P.Z., Cleeman, J.I., Donato, K.A., et al. (2009) Harmonizing the Metabolic Syndrome. A Joint Interim Statement of the International Diabetes Federation Task Force on Epidemi- 
ology and Prevention; National Heart, Lung, and Blood Institute; American Heart Association; World Heart Federation; International Atherosclerosis Society; and International Association for the Study of Obesity. Circulation, 120, 16401645. http://dx.doi.org/10.1161/CIRCULATIONAHA.109.192644

[19] Expert Panel on Detection, Evaluation, and Treatment of High Blood Cholesterol in Adults (2001) Executive Summary of the Third Report of the National Cholesterol Education Program (NCEP) Expert Panel on Detection, Evaluation, and Treatment of High Blood Cholesterol in Adults (Adult Treatment Panel III). JAMA, 285, 2486-2497. http://dx.doi.org/10.1001/jama.285.19.2486

[20] Lottenberg, A.S., Glezer, A. and Turatti, L.A. (2007) Metabolic Syndrome: Identifying Risk Factors. Jornal de Pediatria, 83, 204-208. http://dx.doi.org/10.1590/S0021-75572007000700012

[21] Obokata, M., Negishi, K., Ohyama, Y., Okada, H., Imai, K. and Kurabayashi, M. (2015) A Risk Score with Additional Four Independent Factors to Predict the Incidence and Recovery from Metabolic Syndrome: Development and Validation in Large Japanese Cohorts. PLoS ONE, 10, e0133884. http://dx.doi.org/10.1371/journal.pone.0133884

[22] Hajian-Tilaki, K. (2015) Metabolic Syndrome and Its Associated Risk Factors in Iranian Adults: A Systematic Review. Caspian Journal of Internal Medicine, 6, 51-61.

[23] Pelegrini, A., Santos-Silva, D., Petroski, E.L. and Glaner, M.F. (2015) Prevalência de Síndrome Metabólica em Homens. Revista de Salud Pública, 12, 635-646.

[24] Hajian-Tialki, K. and Heidari, B. (2012) Prevalence of Overweight and Obesity and Their Association with Physical Activity Pattern among Iranian Adolescents Aged 12 - 17 Years. Public Health Nutrition, 15, 2246-2252. http://dx.doi.org/10.1017/S1368980012001048

[25] Levitt, N.S. (2008) Diabetes in Africa: Epidemiology, Management and Healthcare Challenges. Heart, 94, $1376-1382$. http://dx.doi.org/10.1136/hrt.2008.147306

[26] Nicholl, A., du Heaume, M., Mori, T.A., Beilin, L.J., Oddy, W.H., Bremner, A.P., et al. (2014) Higher Breakfast Glycaemic Load Is Associated with Increased Metabolic Syndrome Risk, Including Lower HDL-Cholesterol Concentrations and Increased TAG Concentrations, in Adolescent Girls. British Journal of Nutrition, 112, 1974-1983. http://dx.doi.org/10.1017/S0007114514003092

[27] Leão, L.S.C.S., Moraes, M.M., Carvalho, G.X. and Koifman, R.J. (2011) Nutritional Interventions on Metabolic Syndrome: A Systematic Review. Arquivos Brasileiros de Cardiologia, 97, 260-265. http://dx.doi.org/10.1590/S0066-782X2011001200012

[28] Bitzur, R., Cohen, H., Kamari, Y., Shaish, A. and Harats, D. (2009) Triglycerides and HDL Cholesterol. Stars or Second Leads in Diabetes? Diabetes Care, 32, 373-377. http://dx.doi.org/10.2337/dc09-S343

[29] Ford, E.S., Giles, W.H. and Dietz, W.H. (2002) Prevalence of the Metabolic Syndrome among US Adults: Findings from the Third National Health and Nutrition Examination Survey. JAMA, 287, 356-359. http://dx.doi.org/10.1001/jama.287.3.356

[30] Leão, L.S.C.S., Barros, E.G. and Koifman, R.J. (2010) Metabolic Syndrome Prevalence in Adults Referenced to Nutrition Clinic in Rio de Janeiro, Brazil. Revista Brasileira de Cardiologia, 23, 93-100.

[31] Costa, M.F. and Valle, J. (2012) Metabolic Syndrome: Prevalence and Association with Cardiovascular Disease in Adults. Costa, 7, 119-132. http://www.e-publicacoes.uerj.br/index.php/demetra/article/view/3598/2978\#.VdPb5rJViko

[32] Brazil Ministry of Health (2011) Secretariat of Health Surveillance. Strategic Action Plan for Dealing with Chronic Noncommunicable Diseases (NCDs) in Brazil from 2011 to 2022. Ministry of Health, Brasília (DF). http://bvsms.saude.gov.br/bvs/publicacoes/plano acoes enfrent dent 2011.pdf

[33] Pimenta, A.M., Felisbino-Mendes, M.S. and Velasquez-Melendez, G. (2013) Clustering and Combining Pattern of Metabolic Syndrome Components in a Rural Brazilian Adult Population. Sao Paulo Medical Journal, 131, 213-219. http://dx.doi.org/10.1590/1516-3180.2013.1314326

[34] Okafor, C.I. (2012) The Metabolic Syndrome in Africa: Current Trends. Indian Journal of Endocrinology and Metabolism, 16, 56-66. http://dx.doi.org/10.4103/2230-8210.91191

[35] Pedro Magalhães, P., Capingana, D.P. and Mill, J.G. (2014) Prevalence of the Metabolic Syndrome and Determination of Optimal Cut-Off Values of Waist Circumference in University Employees from Angola. Cardiovascular Journal of Africa, 25, 27-33. http://dx.doi.org/10.5830/CVJA-2013-086

[36] Delshad, M., Ghanbarian, A., Ghaleh, N.R., Amirshekari, G., Askari, S. and Azizi, F. (2015) Reliability and Validity of the Modifiable Activity Questionnaire for an Iranian Urban Adolescent Population. International Journal of Preventive Medicine, 6, 3. http://dx.doi.org/10.4103/2008-7802.151433

[37] Miglani, N., Bains, K. and Singh, P. (2014) Diet and Physical Activity in Relation to Metabolic Syndrome among Urban Indian Men and Women. Ecology of Food and Nutrition, 54, 43-53. http://dx.doi.org/10.1080/03670244.2014.947403 